\title{
Plain and PVA Fibre-Reinforced Geopolymer Compact Tension Specimen Critical Area Surface Composition Assessment
}

\author{
Rihards Gailitis \\ Faculty of Civil Engineering \\ Riga Technical University \\ Riga, Latvia \\ rihards.gailitis@edu.rtu.lv \\ Patrycja Bazan \\ Faculty of Materials Science and \\ Physics \\ Cracow University of Technology \\ Krakow, Poland \\ patrycja.bazan@pk.edu.pl
}

\author{
Andina Sprince \\ Faculty of Civil Engineering \\ Riga Technical University \\ Riga, Latvia \\ andina.sprince@rtu.lv \\ Kinga Korniejenko \\ Faculty of Materials Science and \\ Physics \\ Cracow University of Technology \\ Krakow, Poland \\ kkorniej@gmail.com
}

\author{
Leonids Pakrastins \\ Faculty of Civil Engineering \\ Riga Technical University \\ Riga, Latvia \\ leonids.pakrastins@rtu.lv
}

\begin{abstract}
For more than 40 years, low calcium alkaliactivated cement composite, or in other words, geopolymer, has been around. In recent years there has been increased interest in this material and its properties. It is mainly due to the claim that geopolymer is the cement of the future. This claim is based on environmental factors. For instance, the $\mathrm{CO}_{2}$ emissions for geopolymer binder can be up to 6 less than for Portland cement binder. Most of the researches regarding geopolymer composite properties examine only mechanical and long-term properties in compression. There has been a lack of long-term tests in tension due to difficulties in performing them. As the tensile stresses are an essential part of structure assessment, it is necessary to evaluate new material properties as thoroughly as possible. Due to the nature of geopolymer specimen hardening (polymerisation), there is a difference in modulus of elasticity development and shrinkage caused by binding that could have factors that regular Portland cement specimens do not.
\end{abstract}

This article aims to evaluate the surface composition of plain and 1\% PVA reinforced geopolymer compact tension specimens that have been subjected to creep and shrinkage tests. Specimen cross-section images were acquired using the scanning electron microscope (SEM). Using the quantitative image analysis method, amounts of cross-section composition elements are determined. Furthermore, the amount of cracks is determined and compared between plain and PVA fiberreinforced specimens.
It has been determined that even though 1\% of PVA fibre-reinforced specimens have lower tensile strength, their creep and shrinkage strains are lower, and the number of microcracks at the notch base of the specimen. Still, it has to be acknowledged that the amount of air voids in all analysed specimens is relatively high.

Keywords - Geopolymer composite, long-term properties, creep, shrinkage, quantitative image analysis

\section{INTRODUCTION}

Alkali-activated materials have been known as an alternative binder to ordinary Portland cement (OPC) mainly due to environmental reasons. Year by year, cement consumption goes up and now is responsible for more than 1.5 billion tonnes of $\mathrm{CO}_{2}$ emission annually or, in other words, 5 to $8 \%$ of global $\mathrm{CO}_{2}$ emissions. This due to limestone decomposition to generate reactive calcium silicate and aluminate phases [1]-[4]. By using alkaliactivated materials, environmental benefits are gained in two ways. One is waste material stockpile reduction because, in alkali-activated material, such materials are used like fly ash, blast furnace slag, etc., as a part of the binder. The second way is by using these industrial waste materials as binder components, the necessity for OPC is reduced, and therefore, the $\mathrm{CO} 2$ is reduced. It has been estimated that by replacing OPC as a binder altogether with a geopolymer matrix, the emitted $\mathrm{CO}_{2}$ level can be reduced 
up to $46 \%$ [5], [6]. The negative aspect of binder change from OPC to geopolymer shows in cost increase, approximately up to $39 \%$ [7].

Alkali-activated blast furnace slag cement types have been studied since the 1930s, but research in alkaliactivated composites and geopolymers has increased significantly since the 1980s [1]. Geopolymer is a low calcium alkali-activated binder formed because of silicon and aluminium reactions activated by hydroxide silicates from sodium and potassium hydroxide solutions [7], [8]. The main issue regarding the wide usage of geopolymer composites in construction is mainly because there is a need for increased temperature for proper binder hardening. In fact, for sufficient polymerisation, composite has to be subjected to temperature from 40 to $100^{\circ} \mathrm{C}$ (depending on fly ash or slag type and alkali activator) and heated in this temperature from 12 to 48 hours and more, therefore, preventing any on-site construction works [9].

Geopolymer composites have similar compressive strength to OPC-based composites. The difference between geopolymer and OPC composites is that geopolymer composites will achieve $85 \%$ of their final compressive strength in the first 48 hours [10]. Long-term property geopolymer composites have 78\% less shrinkage and 50\% less creep strains than foamed OPC-based composite and a bit larger creep and shrinkage strains than OPC composite [11].

Creep and shrinkage are very well-known phenomenon for cement and similar binder-based composites. These phenomenons may influence the lifetime of structures. Most creep and shrinkage happen in the first ten years of the composite's lifetime. Cement and cement-like materials are considered to have insufficient tensile strain capacity and low tensile strength. Consequently, they are brittle and susceptible to cracking. As performing creep test in tension is quite difficult and there are differences in creep and shrinkage mechanisms in compression and tension, it is necessary not only to develop and carry out these kinds of tests but also to determine factors that are influencing long-term properties in tension [12]-[16].

This article focuses on determining the differences in compact tension (CT) specimen polished section sample surface compositions after creep and shrinkage tests. The polished section's specific zone is marked. The images taken and quantitively analysed to determine whether the 1\% PVA fibre reinforcement incorporation has a significant effect on sample microstructure and, therefore, influence long-term properties.

\section{MATERIALS AND METHODS}

For long-term tests, two types of geopolymer composites were prepared. Geopolymer specimen matrixes were based on fly ash sourced from the power plant based in Skawina city (Poland). The fly ash contains spherical aluminosilicate particles and contains oxides such as $\mathrm{SiO} 2$ (47.81\%), Al2O3 (22.80\%). The high value of $\mathrm{SiO} 2$ and $\mathrm{Al} 2 \mathrm{O} 3$ allows polymerisation [17].
Geopolymer specimens were prepared using sodium promoter, fly ash, and sand (sand and fly ash ratio - 1:1). The geopolymer activation process has been made by $10 \mathrm{M}$ $\mathrm{NaOH}$ solution and the sodium silicate solution (at a rate of $1: 2.5)$. The technical $\mathrm{NaOH}$ in flake form and tap water with sodium silicate R-145 solution is used to make the composite solution. The alkaline solution was prepared by pouring sodium silicate and water over solid sodium hydroxide into sodium silicate and water aqueous solution. The solution was mixed, and the temperature was stabilised. The fly ash, sand, and alkaline solution were mixed for about 15 minutes using a low-speed mixing machine (to achieve homogenous paste). Then the geopolymers were poured into the plastic moulds, as is shown in Fig.1. The specimens were hand-formed, and then the air bubbles were removed by vibrating the mass. Moulds were heated in the laboratory dryer for $24 \mathrm{~h}$ at 75 ${ }^{\circ} \mathrm{C}$. Then, the specimens were unmolded. All the geopolymer specimen preparation was done at Cracow University of Technology (CUT), Poland.

The mixes were moulded into cube moulds 150x150x150mm. The mixing procedure is shown in Fig. 1.

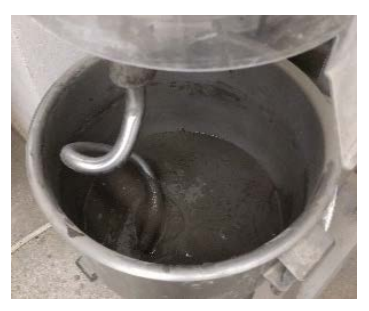

(a)

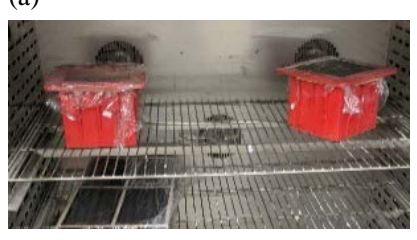

(c)

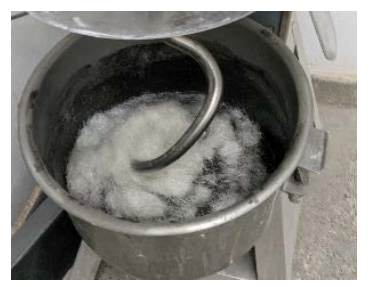

(b)

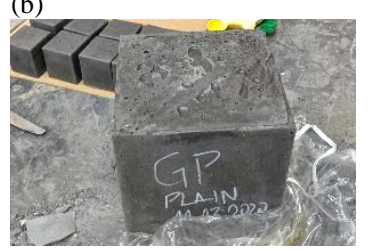

(d)
Fig. 1. Plain (a) and fibre-reinforced (b) geopolymer composite mixing and moulding (c, d) process, CUT lab

For long-term testing purposes, each of the cubes was cut to the tile-shaped CT specimens with a thickness of $15 \mathrm{~mm}$. Each of the tile-shaped specimens had grip $20 \mathrm{~mm}$ holes drilled, and 2mm notch sawed according to ASTM E647 [18]. The rules of ASTM E647 for specimens preparation, please see Fig. 2 (b). The actual prepared CT dimensions are shown in Fig. 2 (a). 


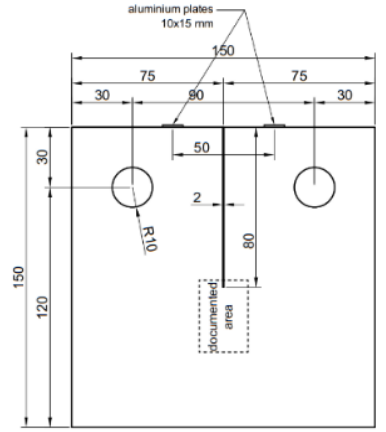

(a)

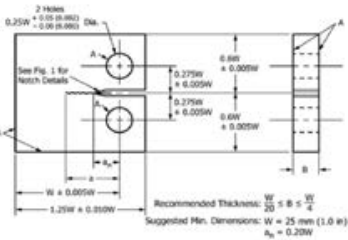

(b)

Fig. 2. Geometry of the Compact Tension (CT) specimen [18], [19]

Compact tension specimens for the creep test were loaded with $20 \%$ of their tensile strength, and shrinkage specimens were kept in the same environment as the creep specimens (*without loading). Strain readings were done simultaneously for both tests. Tests were carried out for 91 days.

When long-term testing was done, each of the CT specimens had their notch base area drilled out. In Fig. 3 $(\mathrm{a}, \mathrm{b}, \mathrm{c})$ drilling process is shown.

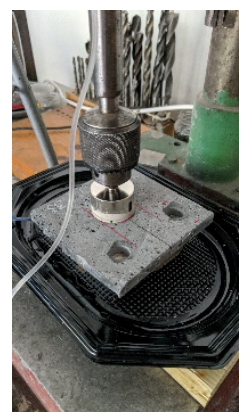

(a)

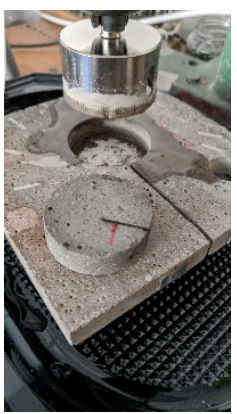

(b)

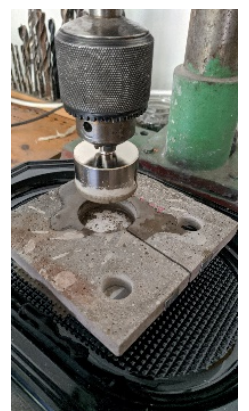

(c)
Fig. 3. CT specimen notch base sample drilling process, RTU lab

When areas for polished section samples were drilled out, they were ground and polished with various compounds at various speeds and durations. The polishing and grinding are done with Mecatech 334 automatic single station polishing machine. The polishing sequence is shown in Table 1.

TABLE 1 SAMPLE SURFACE POLISHING SEQUENCE

\begin{tabular}{|l|l|l|l|}
\hline $\begin{array}{c}\text { Polishing } \\
\text { stage } \\
\text { number }\end{array}$ & $\begin{array}{c}\text { Polishing } \\
\text { compound } \\
\text { (sandpaper } \\
\text { or paste } \\
\text { grade) type }\end{array}$ & $\begin{array}{c}\text { Polishing } \\
\text { cycle time, } \\
\text { minutes }\end{array}$ & $\begin{array}{c}\text { Compression } \\
\text { force to } \\
\text { sample } \\
\text { polishing } \\
\text { surface, daN }\end{array}$ \\
\hline 1. & P180 & 2 & 2.5 \\
\hline 2. & $\mathrm{P} 320$ & 2 & 2.5 \\
\hline 3. & $\mathrm{P} 600$ & 2 & 2.5 \\
\hline 4. & $\mathrm{P} 1000$ & 2 & 2.5 \\
\hline 5. & $\mathrm{P} 1200$ & 2 & 2.5 \\
\hline 6. & $3 \mu \mathrm{m}$ & 4 & 2.5 \\
\hline
\end{tabular}

The polishing procedure is shown in Fig.4 (a,b).

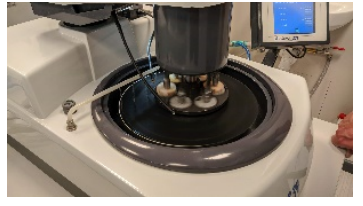

(a)

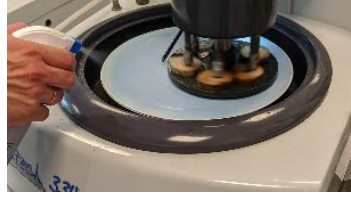

(b)
Fig. 4. Notch base samples grinding (a) and polishing (b) process, RTU lab

After grinding and polishing, samples are dried in the chamber at $40^{\circ} \mathrm{C}$ for 48 hours to release all the excess moisture from grinding. When samples are dried, they are placed in zip-lock bags together with silica gel so that samples stay dried for longer.

At the beginning of the samples' SEM microanalysis, the samples are covered with gold (Fig. 5 (a)). After the sample covering the specific zone on it is marked, the specific area's tracing on the polished section would be done more precisely (Fig. 5 (b)).

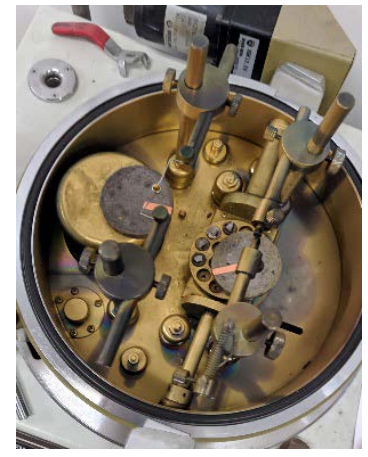

(a)

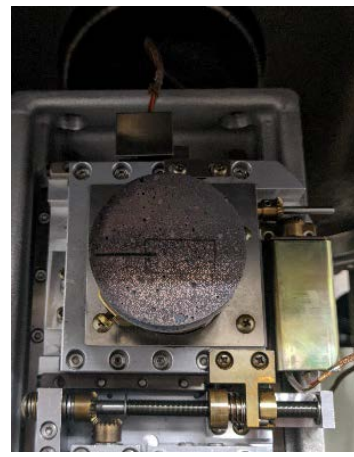

(b)
Fig. 5. CT specimen polished section sample covering with gold (a) and placement in SEM vacuum chamber (b), CUT lab

The marked zone on the sample in Fig. 5(b) is $10 \times 20$ mm. SEM microanalysis is done in JEOL JSM-820. Achieved images are compiled and divided into layers and analysed using Adobe Photoshop CC. Dividing into layers is based on the partition type visible within the analysed cross-section. Division layers are matrix, filler, air-voids, and reinforcement. For each specific layer, an RGB tone is allocated. The process is shown in Fig. 6(a,b,c,d).

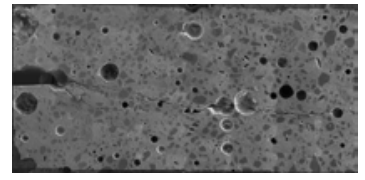

(a)

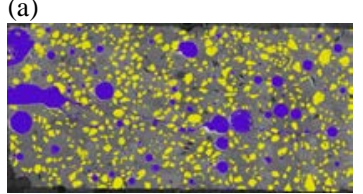

(c)

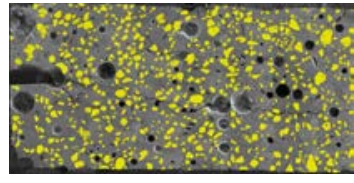

(b)

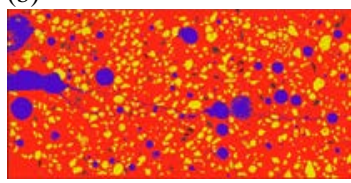

(d)
Fig. 6. Image dividing sequence into layers 
When the image dividing and RGB tone selection were made, the amount of specific RGB pixels was counted. This way, the composition amount of the studied cross-section was acquired.

\section{RESULTS AND DISCUSSION}

The tensile strength of the CT specimens at the beginning of the long-term tests is compiled in Table 2.

TABLE 2 TENSILE STRENGTH OF CT SPECIMENS

\begin{tabular}{|l|c|c|}
\hline \multicolumn{1}{|c|}{ Mix type } & $\begin{array}{c}\text { Ultimate tensile } \\
\text { load value, average } \\
\text { (kN) }\end{array}$ & $\begin{array}{c}\text { Average tensile } \\
\text { strength, MPa }\end{array}$ \\
\hline $\begin{array}{l}\text { Plain geopolymer } \\
\text { composite }\end{array}$ & 0.2767 & 5.1326 \\
\hline $\begin{array}{l}\text { Geopolymer } \\
\text { composite with 1\% } \\
\text { PVA }\end{array}$ & 0.2667 & 4.9471 \\
\hline
\end{tabular}

When the tensile strength values are determined, then load for the creep test is calculated. Creep and shrinkage tests are carried out for 91 days. The creep and shrinkage curves are shown in Fig.7.

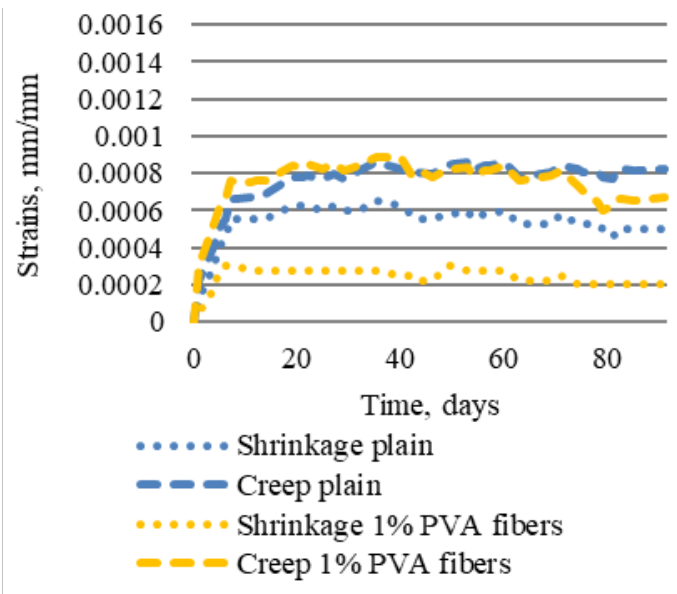

Fig. 7. Plain and fibre-reinforced geopolymer composite CT specimen creep and shrinkage strains

From Fig. 7, it is apparent that 1\% PVA fibre incorporation into geopolymer composite does not bear any significant improvements in creep properties. The creep curves for plain and reinforced specimens are the same. As for the shrinkage strain curves, there is a significant difference between plain and fibre-reinforced specimens. The difference here is, on average, a $54.21 \%$ decrease in shrinkage strains for reinforced specimens in contrast to plain specimens.

Also, it is visible in Fig.7 that reinforced specimens have a significant reduction on day $70^{\text {th }}$. This leads to thinking that something has happened to one or more specimens that could have caused this reduction in strains and loss of load-bearing capability. To further elaborate on this decrease in strains, the quantitative surface composition analysis is done for the notch-based polished sections. The results of the analysis are compiled in Table 3.
TABLE 3 CROSS-SECTION COMPOSITION OF CT SPECIMENS

\begin{tabular}{|c|c|c|c|c|c|}
\hline $\begin{array}{l}\text { Test } \\
\text { type }\end{array}$ & $\begin{array}{l}\text { Mix } \\
\text { type }\end{array}$ & $\begin{array}{c}\text { Matrix } \\
\text { amount, \% }\end{array}$ & $\begin{array}{c}\text { Filler } \\
\text { amount, \% }\end{array}$ & $\begin{array}{c}\begin{array}{c}\text { Air void } \\
\text { amount, } \\
\%\end{array} \\
\end{array}$ & $\begin{array}{c}\text { Fiber } \\
\text { amount, } \\
\%\end{array}$ \\
\hline \multirow[b]{2}{*}{ 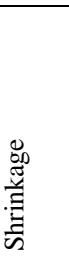 } & $\frac{\pi}{\frac{\pi}{\alpha}}$ & 75.48 & 16.93 & 7.59 & - \\
\hline & 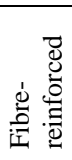 & 75.75 & 14.07 & 9.47 & 0.71 \\
\hline \multirow[b]{2}{*}{ :ँّ } & $\frac{\text { 营 }}{\sim}$ & 77.39 & 15.60 & 7.01 & - \\
\hline & 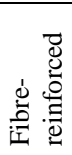 & $\begin{array}{l}74.98 \\
\end{array}$ & 14.58 & 9.51 & 0.93 \\
\hline
\end{tabular}

As shown in Table 3, the reinforced samples show higher amounts of air voids than plain samples. On average, the increase is $19.85 \%$ and $26.29 \%$ for reinforced shrinkage and creep specimens, respectively. Further analysing results, there are differences between plain and reinforced samples. For instance, plain samples that have been subjected to load (samples from creep specimens) show a lower amount of air voids than those that have not been subjected to any load. The decrease to loaded specimens on average is $7.64 \%$. The same is not happening with fibrereinforced samples. There is a slight visible increase of $0.42 \%$ in air void amount for loaded samples for them. This amount is negligible and leads to thinking that even specimens are tested only in tension; there is still some compression happening to specimens. As these compression strains are quite low, the fibre reinforcement does not allow compression effects to occur in the crosssection.

At the microanalysis, it was also discovered that fibrereinforced samples have a significantly higher amount of micro-cracks that had developed a macro crack that would explain the creep curve drop in one polished section case Fig. 7 on day $70^{\text {th }}$. In Fig. 8 (a,b), the actual image is shown.

In Fig. 8 (b), there is directly visible one main crack that starts at the CT specimen base and goes throughout the sample.

Further analysing the surface microanalysis results in Table 3 shows a common trend that all of the reinforced samples have lower filler amounts than plain samples. The filler amount is relatively stable in context whether samples have or have not been subjected to any load. The difference between shrinkage and creep samples for reinforced samples is $3.51 \%$, and for plain samples, $7.86 \%$.

The matrix amount of all the samples is similar to all other entity amounts. 
Environment. Technology. Resources. Rezekne, Latvia Proceedings of the $13^{\text {th }}$ International Scientific and Practical Conference. Volume 3, 72-77
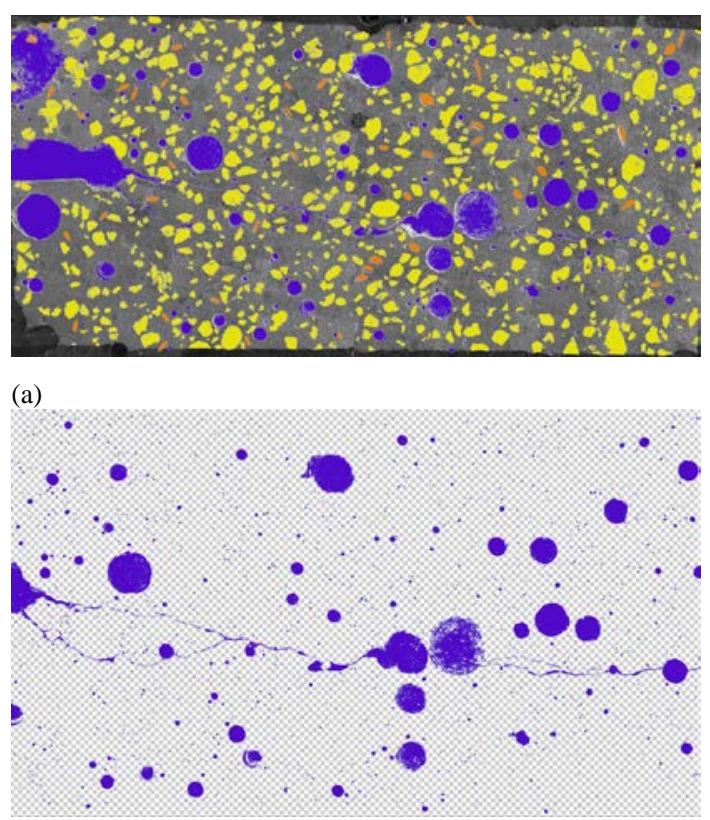

(b)

Fig. 8. Fibre-reinforced CT specimen notch base sample air void, reinforcement, filler placement (a), and air void/crack placement (b) in polished section

\section{CONCLUSIONS}

Such conclusions can be drawn from the results:

1. The air inclusion amount for the fibre-reinforced samples is significantly higher and is not influenced by tension strains. It is 19.85 and $26.29 \%$ higher than plain shrinkage and creep samples correspondingly.

2. Increased air void amount and low amounts of fibre reinforcement increase the possibility of sample cracking and load-bearing capability loss. Fibrereinforced specimens show $3.7 \%$ lower tensile strength and structural imperfections due to the small fibre reinforcement amount.

3. Reinforced samples show lower amounts of filler in them. In contrast to plain specimens, the filler amount for reinforced shrinkage and creep samples is $3.51 \%$ and $7.86 \%$, respectively.

4. Fibre reinforcement does not significantly affect creep properties in tension but affects shrinkage strain reduction. On average, shrinkage strains are $54.21 \%$ lower for fibre-reinforced specimens than plain geopolymer CT specimens.

\section{ACKNOWLEDGEMENTS}

This work has been supported by the European Regional Development Fund within the Activity 1.1.1.2 "Post-doctoral Research Aid" of the Specific Aid Objective 1.1.1 "To increase the research and innovative capacity of scientific institutions of Latvia and the ability to attract external financing, investing in human resources and infrastructure" of the Operational Programme "Growth and Employment" (No.1.1.1.2/VIAA/3/19/401).

This publication was supported by Riga Technical University's Doctoral Grant programme.

\section{REFERENCES}

[1] N. Alharbi, B. Varela, and R. Hailstone, “Alkali-activated slag characterization by scanning electron microscopy , X- ray microanalysis and nuclear magnetic resonance spectroscopy,” Mater. Charact., vol. 168, no. July, p. 110504, 2020, doi: 10.1016/j.matchar.2020.110504.

[2] C. Shi, A. F. Jiménez, and A. Palomo, "New cements for the 21st century: The pursuit of an alternative to Portland cement," Cem. Concr. Res., vol. 41, no. 7, pp. 750-763, 2011, doi: 10.1016/j.cemconres.2011.03.016.

[3] W. Tu, Y. Zhu, G. Fang, X. Wang, and M. Zhang, "Internal curing of alkali-activated fly ash-slag pastes using superabsorbent polymer,” Cem. Concr. Res., vol. 116, no. December 2018, pp. 179-190, 2019, doi: 10.1016/j.cemconres.2018.11.018.

[4] K. Kermeli et al., "The scope for better industry representation in long-term energy models: Modeling the cement industry,” Appl. Energy, vol. 240, no. March 2018, pp. 964-985, 2019, doi: 10.1016/j.apenergy.2019.01.252.

[5] L. Sele, D. Bajare, G. Bumanis, and L. Dembovska, "Alkali Activated Binders Based on Metakaolin,” vol. 1, pp. 200-204, 2015, doi: 10.17770/etr2015vol1.204.

[6] A. M. Rashad and G. M. F. Essa, "Effect of ceramic waste powder on alkali-activated slag pastes cured in hot weather after exposure to elevated temperature," Cem. Concr. Compos., vol. 111, no. September 2019, p. 103617, 2020, doi: 10.1016/j.cemconcomp.2020.103617.

[7] E. Linul et al., "Quasi-Static Mechanical Characterization of Lightweight Fly Ash-Based Geopolymer Foams,” IOP Conf. Ser. Mater. Sci. Eng., vol. 416, no. 1, 2018, doi: 10.1088/1757899X/416/1/012102.

[8] S. Yan et al., "Effects of high-temperature heat treatment on the microstructure and mechanical performance of hybrid $\mathrm{C} \mathrm{f}-\mathrm{SiC} \mathrm{f}$ (Al 2 O 3p ) reinforced geopolymer composites,” Compos. Part B Eng., vol. 114, pp. 289-298, 2017, doi: 10.1016/j.compositesb.2017.02.011.

[9] S. H. Kang, Y. Jeong, M. O. Kim, and J. Moon, "Pozzolanic reaction on alkali-activated Class $\mathrm{F}$ fly ash for ambient condition curable structural materials,” Constr. Build. Mater., vol. 218, pp. 235-244, 2019, doi: 10.1016/j.conbuildmat.2019.05.129.

[10] L. N. Assi, K. Carter, E. Deaver, and P. Ziehl, "Review of availability of source materials for geopolymer/sustainable concrete,” J. Clean. Prod., vol. 263, p. 121477, 2020, doi: 10.1016/j.jclepro.2020.121477.

[11] M. Amran et al., "Fibre-reinforced foamed concretes: A review," Materials (Basel)., vol. 13, no. 19, pp. 1-36, 2020, doi: 10.3390/ma13194323.

[12] M. Nastic, E. C. Bentz, O. Kwon, V. Papanikolaou, and J. Tcherner, "Shrinkage and creep strains of concrete exposed to low relative humidity and high temperature environments," Nucl. Eng. Des., vol. 352, no. June, p. 110154, 2019, doi: 10.1016/j.nucengdes.2019.110154.

[13] I. Boumakis, G. Di Luzio, M. Marcon, J. Vorel, and R. WanWendner, "Discrete element framework for modeling tertiary creep of concrete in tension and compression," Eng. Fract. Mech., vol. 200, no. July, pp. 263-282, 2018, doi: 10.1016/j.engfracmech.2018.07.006.

[14] P. Rossi, J. L. Tailhan, and F. Le Maou, “Comparison of concrete creep in tension and in compression: Influence of concrete age at loading and drying conditions,” Cem. Concr. Res., vol. 51, pp. 7884, 2013, doi: 10.1016/j.cemconres.2013.04.001.

[15] N. Ranaivomanana, S. Multon, and A. Turatsinze, "Basic creep of concrete under compression, tension and bending," Constr. Build. 
Mater., vol. 38, pp. 173-180, 2013, doi: 10.1016/j.conbuildmat.2012.08.024.

[16] Z. Q. Cheng, R. Zhao, Y. Yuan, F. Li, A. Castel, and T. Xu, "Ageing coefficient for early age tensile creep of blended slag and low calcium fly ash geopolymer concrete," Constr. Build. Mater.,
vol. 262
119855 ,
2020 ,
doi: 10.1016/j.conbuildmat.2020.119855

[17] K. Korniejenko, M. Łach, M. Hebdowska-Krupa, and J. Mikuła, "The mechanical properties of flax and hemp fibres reinforced geopolymer composites,” IOP Conf. Ser. Mater. Sci. Eng., vol. 379, no. 1, 2018, doi: 10.1088/1757-899X/379/1/012023.

[18] ASTM, "E647 - Standard Test Method for Measurement of Fatigue Crack Growth Rates,” ASTM B. Stand., vol. 03, no. July, pp. 1-49, 2016, doi: 10.1520/E0647-15E01.2.

[19] A. Sprince, L. Pakrastinsh, B. Baskers, and L. Gaile, "Crack development research in extra fine aggregate cement composites," Vide. Tehnol. Resur. - Environ. Technol. Resour., vol. 1, pp. 205208, 2015, doi: 10.17770/etr2015vol1.199. 